\title{
PROSPECTIVE ASSESSMENT OF THE CLINICAL, RADIOGRAPHIC AND FUNCTIONAL EVOLUTION OF TREATMENT FOR UNSTABLE TROCHANTERIC FRACTURES OF THE FEMUR USING A CEPHALOMEDULLARY NAIL
}

Richard Armelin Borger ${ }^{1}$, Frederico Araújo Leite ${ }^{2}$, Rodrigo Pires de Araújo², Thiago Ferreira Nunes Pereira², Roberto Dantas Queiroz ${ }^{3}$

\section{ABSTRACT}

Objective: To assess the clinical, radiological and functional evolution of osteosynthesis using a cephalomedullary nail, in unstable trochanteric fractures of the femur, over a one-year postoperative follow-up. Methods: Fourteen men and 23 women of mean age 77.7 years were evaluated. Twenty-seven of them had fractures classified as $\mathrm{AO} / \mathrm{ASIF} 31 \mathrm{~A} 2$ and ten as $31 \mathrm{~A} 3$. The patients were evaluated clinically, radiologically and functionally one week, two weeks, one month, two months, six months and one year after the operation. Results: The clinical complications comprised five cases of death, one case of calcaneal ulcer, one case of acute arterial obstruction and two cases of deep vein thrombosis. The radiographic evaluation showed that the mean cervicodiaphyseal angle in the immediate postoperative period was $132.5^{\circ}$. The mean tip-apex index was $22.8 \mathrm{~mm}$. After one year, the mean cervicodiaphyseal angle was $131.7^{\circ}$. Fracture consolidation was seen in all the patients six months after the operation, except in one case that presented cut-out. There were no cases of fracture below the implant. The functional evaluation using the Harris score after one year showed a mean of 69.3 points. The evaluation of walking progress showed that after one year, $40.6 \%$ of the patients had the same ability to walk that they had before the fracture. The visual analogue pain scale showed that a significant decrease in pain complaints occurred, going from 5.19 in the first week to 2.25 after 1 year. Conclusion: Osteosynthesis using a cephalomedullary nail resulted in low rates of clinical and mechanical complications and adequate functional outcomes.

Keywords - Hip Fractures; Fracture Fixation, Internal/methods; Femoral Fractures; Bone Nails; Fracture Healing; Postoperative Complications.

\section{INTRODUCTION}

Trochanteric fractures are extracapsular fractures of the proximal femur involving the area between the greater and lesser trochanters. They are common fractures in the elderly population because of osteoporosis, and are mainly associated with low-energy trauma, such as falling from the individual's own height.

The incidence of fractures of the proximal femur has increased significantly over recent decades and is expected to double over the next 25 years because of increasing life expectancy among the population ${ }^{(1)}$. It has been estimated that nine out of every ten trochanteric fractures occur in individuals over the age of 65 years $^{(2)}$. Around one in every 1000 inhabitants per year, in developed countries, is affected by fractures of the proximal femur ${ }^{(3)}$.

Advanced age and associated comorbidities are responsible for high morbidity and mortality and for the high cost of treatment. In the United States, the expenditure is expected to rise from 8.7 billion in

1- Attending Physician in the Hip Group, Orthopedics and Traumatology Service, State Public Servants' Hospital (HSPE), IAMSPE, São Paulo, Brazil.

2- Resident Physician in the Orthopedics and Traumatology Service, State Public Servants' Hospital (HSPE), IAMSPE, São Paulo, Brazil.

3- Physician and Head of the Orthopedics and Traumatology Service, State Public Servants' Hospital (HSPE), IAMSPE, São Paulo, Brazil.

Work performed at the State Public Servants' Hospital (HSPE), IAMSPE, São Paulo.

Correspondence: Rua Borges Lagoa, 755, 1ª andar, sala 180 -04038-034 - São Paulo, SP - E-mail: robdanqueiroz@globo.com / ortopediahspe@gmail.com

Work received for publication: October 26, 2010; accepted for publication: December 23, 2010.

The authors declare that there was no conflict of interest in conducting this work 
2009 to 240 billion in 2040 . The mortality rate after six months ranges from 12 to $41 \%$ and results mainly from clinical complications such as pulmonary thromboembolism and sepsis ${ }^{(4)}$.

The classification systems most used in the literature are $\mathrm{AO} / \mathrm{ASIF}^{(5)}$ (Figure 1) and the Tronzo system $^{(6)}$ (Figure 2).

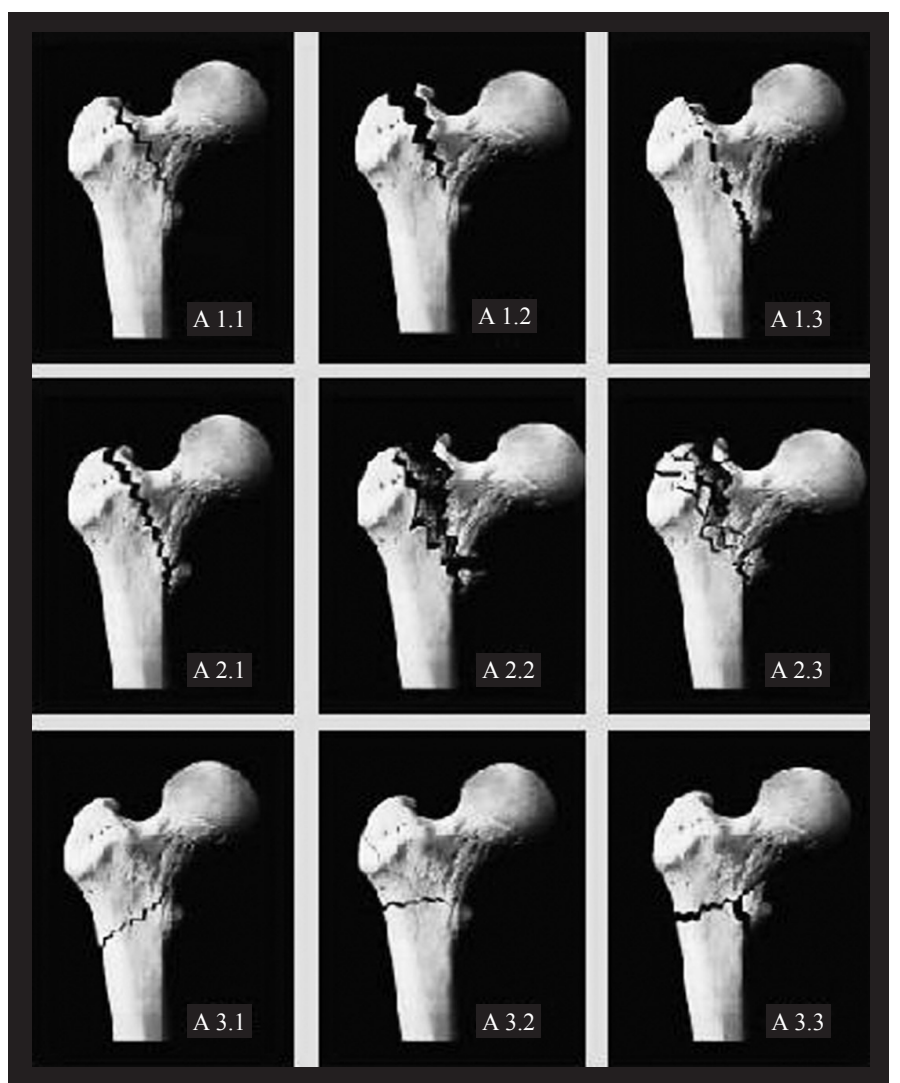

Figure 1 - AO/ASIF classification.

Determination of the fracture pattern in terms of stability is fundamental for assessing the treatment options. Fractures are considered to be unstable in the presence of comminution of the posteromedial cortical bone, reverse obliquity and subtrochanteric extent $^{(2)}$. Unstable fractures are grouped as AO/ASIF 31A2 and 31A3 and Tronzo III, IV and V.

Non-surgical treatment is reserved for patients with comorbidities that put them at unacceptable risk in relation to anesthesia, surgical procedures, or both ${ }^{(2)}$. Through the principle of relative stability, surgical treatment has the aim of achieving functional reduction and stable fixation for pain relief and early return to walking and to the previous state of independence. Although surgical treatment does not change the mortality rate over the first six months,

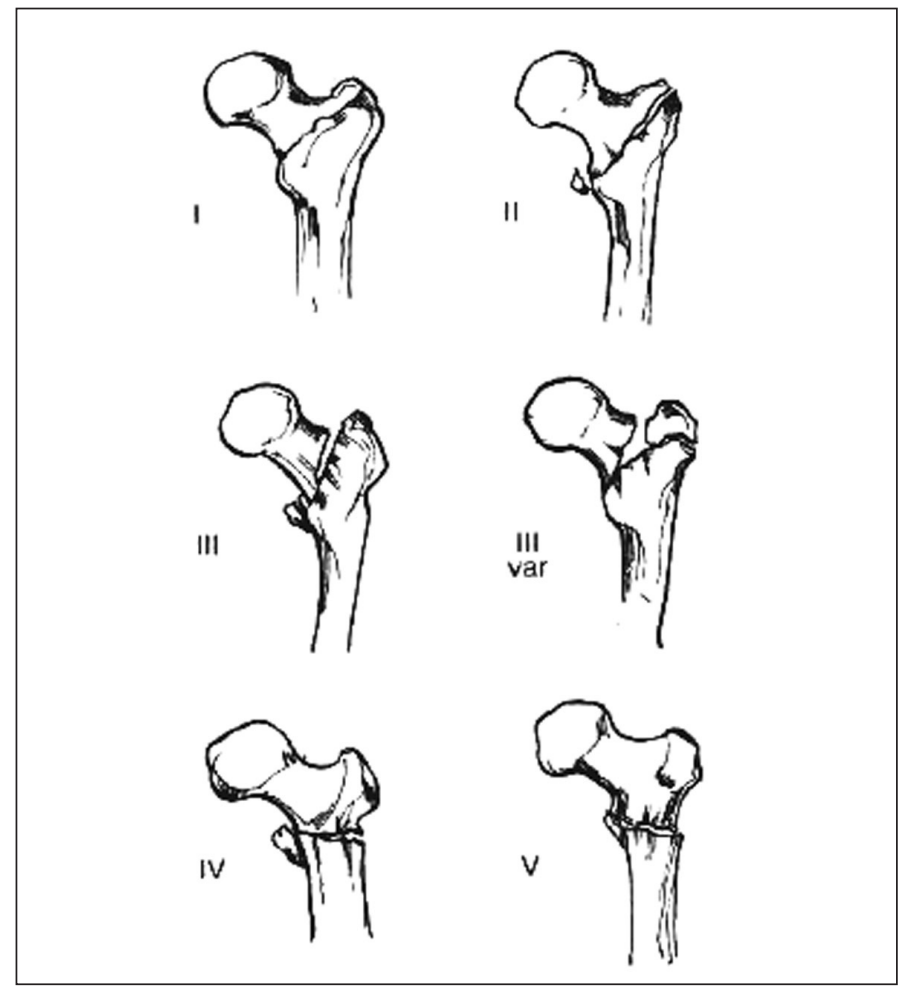

Figure 2 - Tronzo classification.

it diminishes the complications resulting from prolonged restriction to bed $^{(2)}$.

Because of the abundant blood supply in the trochanter region, the rates of osteonecrosis and pseudarthrosis are low, thus favoring surgical treatment via internal fixation. Osteosynthesis of trochanteric fractures is the principal surgical treatment method, although replacement using a prosthesis is occasionally indicated ${ }^{(2)}$.

The result from surgical treatment depends on the fracture pattern, bone quality, reduction and fixation method. Among the mechanical complications from the surgical treatment, varus collapse, uncontrolled shortening and fixation failure (which are more common in unstable fractures) can be highlighted ${ }^{(7)}$.

A variety of fixation devices have been developed to face up to the difficulties in fixation of trochanteric fractures ${ }^{(8)}$. The implants can be intramedullary or extramedullary. The extramedullary implant most frequently used is the sliding hip screw (DHS). For stable fractures, this type of screw is the implant of choice for treating unstable fractures, according to many authors ${ }^{(4,9-11)}$.

Cephalomedullary systems are biomechanically better for reducing flexor moment, because of better rotational control and better control over varus collapse 
and shortening, given that their layout is more medial than extramedullary devices are ${ }^{(12)}$. Several studies have reported that osteosynthesis using cephalomedullary devices promotes faster return to walking, shorter duration of surgery and less blood loss ${ }^{(2,13)}$.

The design of proximal femoral nails has evolved and the nails are now in their third generation. The improvements in the design have reduced the occurrences of some complications like intraoperative fractures and fractures below the nail tip (after the operation). The Targon- $\mathrm{PF}^{\circledR}$ cephalomedullary nail (Figure 3) presents the differential that the cephalic anti-rotation nail and cephalic jacket of the sliding screw are fixed in the femoral nail itself, thereby avoiding the " $Z$ " effect that occurs with other cephalomedullary nails ${ }^{(14)}$ (Figure 4).

The objective of this study was to prospectively assess the clinical, radiological and functional evolution of osteosynthesis using a cephalomedullary nail (Targon- $\mathrm{PF}^{\circledR}$ ), in unstable trochanteric fractures of the femur, over a one-year postoperative follow-up.

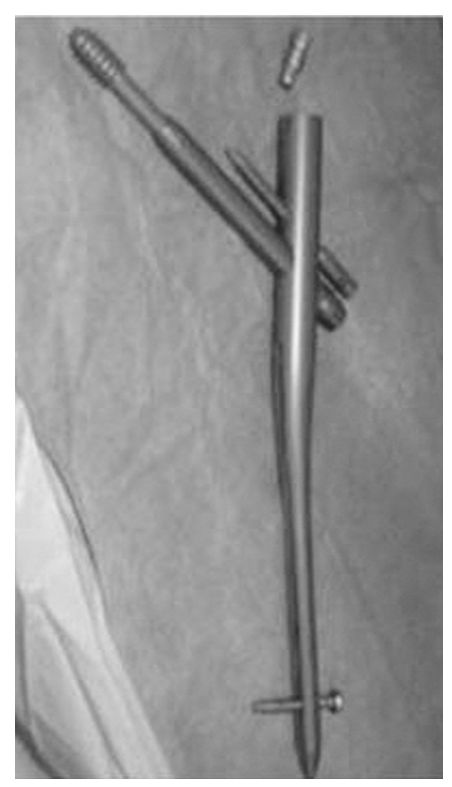

Figure 3 - PF-Targon-PF ${ }^{\circledR}$ nail.

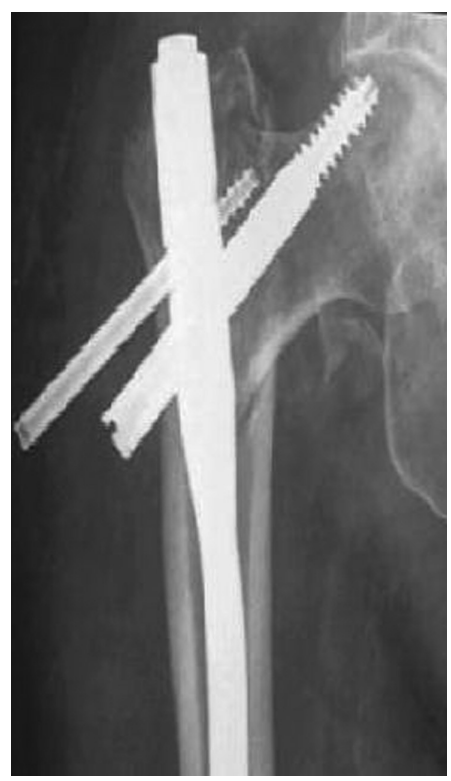

Figure 4 - Anteroposterior radiograph on hip, with "Z" effect.

\section{METHODS}

Between November 2008 and March 2009, 70 patients with trochanteric fractures underwent femoral osteosynthesis. Out of this group, 40 patients underwent osteosynthesis by means of the Targon$-\mathrm{PF}^{\circledR}$ cephalomedullary nail because they presented unstable trochanteric fractures.
The patients included in this study were over 60 years of age, with unstable fractures classified according to the AO/ASIF system as $31 \mathrm{~A} 2$ or $31 \mathrm{~A} 3$. They were included only after they authorized their participation through signing a free and informed consent statement.

The exclusion criteria included the presence of femoral fractures with subtrochanteric extent, pathological fractures due to tumor lesions, previous incapacity to walk and associations with other fractures that would interfere with rehabilitation. Three patients were excluded because they were under 60 years old, because their ages could have caused distortions in the functional assessment of walking. Thus, the final sample was composed of 37 patients.

Fourteen men (37.8\%) and 23 women (62.2\%) were assessed. The right side was affected in $18 \mathrm{ca}-$ ses $(49 \%)$ and the left side in 19 cases $(51 \%)$. The patients' mean age was 77.7 years, with a range from 60 to 95 years. The most common trauma mechanism was a fall from the individual's own height, in 36 cases $(97.3 \%)$, There was one case $(2.7 \%)$ resulting from trauma due to a projectile from a firearm.

All the fractures were classified using the $\mathrm{AO} /$ ASIF and Tronzo classification systems. According to the AO/ASIF system, 27 patients (73\%) presented type $31 \mathrm{~A} 2$ fractures and $10(27 \%)$ had type $31 \mathrm{~A} 3$ fractures. According to the Tronzo classification, 23 patients $(62 \%)$ were in Tronzo III, four $(11 \%)$ were in Tronzo IV and 10 (27\%) patients were in Tronzo V.

Comorbidities were found to be present in 31 patients $(83.8 \%)$. Cardiovascular diseases were seen in 25 patients $(67.5 \%)$, diabetes in $11(29.7 \%)$, Parkinson disease in three $(8.1 \%)$, pulmonary disease in two (5.4\%) and Alzheimer's disease in two (5.4\%). Other comorbidities present included epilepsy, alcoholism, hypothyroidism and chronic kidney failure. There were no comorbidities in six patients $(16.2 \%)$. The patients underwent surgical treatment as soon as their clinical conditions allowed this. The mean time elapsed from hospital admission to the date of the surgery was 7.1 days, with a total mean duration of hospital stay of 9.9 days.

All the patients underwent osteosynthesis using a Targon- $\mathrm{PF}^{\circledR}$ cephalomedullary nail, after indirect reduction of the fracture on the orthopedic table with the aid of fluoroscopy. The nails used had a distal diameter of 10 or $12 \mathrm{~mm}$, single proximal diameter of $17 \mathrm{~mm}$, mediolateral angle of $6^{\circ}$ and cervicodia- 
physeal angles of $125^{\circ}, 130^{\circ}$ and $135^{\circ}$ between the screws in the neck and the axis of the intramedullary nail. The implant was chosen after preoperative planning, according to the cervicodiaphyseal angle of the proximal extremity of the contralateral femur and the diameter of the diaphyseal medullary region.

Drug prophylaxis for deep vein thrombosis (DVT) was administered during the pre and postoperative periods. The patients also received prophylactic antibiotic therapy at the time of induction of anesthesia and for 48 hours after the operation, consisting of cefazolin. During the immediate postoperative period, standard analgesia was administered and the patients were instructed to gradually start to walk again according to their tolerance level.

Through a prospective cohort evaluation with cross-sectional analyses, the patients who underwent osteosynthesis using Targon- $\mathrm{PF}^{\circledR}$ to treat unstable intertrochanteric fractures were assessed one week, two weeks, one month, two months, six months and one years after the operation. At each return visit, clinical, radiological and functional assessments were made on the patients.

The clinical assessment was made by means of analyzing occurrences of clinical complications, including assessment of the mortality rate and its causes.

The radiological assessment included an analysis on the maintenance of the quality of reduction, implant positioning, fracture consolidation and synthesis material failure. The quality of fracture reduction and implant positioning were evaluated by means of radiographic examination during the immediate postoperative period, using anteroposterior (AP) and lateral radiographic views of the proximal femur. The reduction was considered to be ideal when the cervicodiaphyseal angle on the AP radiograph was between $130^{\circ}$ and $135^{\circ}$. If the angle was smaller, the case was considered to be one of varus reduction; and if it was larger, valgus reduction ${ }^{(15)}$. Implant positioning was assessed by means of the tip-apex index ${ }^{(12)}$. Fracture consolidation, varus collapse and synthesis material failure were assessed by means of radiographic analysis at subsequent returns.

The functional assessment was made through analysis on Harris scores, progression of walking and pain scale evolution. At the return visit one year after the operation, a final functional assessment was made using the Harris score (a functional assessment scale with a maximum score of 100 points that includes evaluations on four categories: pain, mobility, daily activities and range of motion). Scores lower than 70 are considered to be poor; between 70 and 80 , reasonable; 80 to 90 , good; and 90 to 100 , excellent $\left(\right.$ Annex 1) ${ }^{(16)}$. During the one-year follow-up, progression of walking and pain scale evolution were assessed. Walking ability was assessed by dividing the patients into five groups: non-walking, walking with the aid of a stick, with crutches and with a walking frame and walking unaided. Before suffering the fracture, $16.2 \%$ of the patients were already using a walking frame, $34.3 \%$ were using a stick and $59.5 \%$ were walking unaided. For the pain evaluation, a visual analogue scale graded from 0 to 10 was used. This scale was directly proportional to the pain level reported by the patient: 0 - free from pain; 1 to 3 - mild pain; 4 to 6 - moderate pain; and 7 to $10-$ severe pain.

The statistical analysis was performed using the SPSS software. Student's t test was used for normally distributed independent variables. Differences were considered to be statistically significant when the rejection level for the nullity hypothesis $(\mathrm{P})$ was 0.05 (significance level of 95\%).

\section{RESULTS}

The clinical assessment over the one-year period showed that 28 patients $(75.7 \%)$ did not have any postoperative clinical complications, while the other nine patients $(24.3 \%)$ presented complications. The mortality rate over the evaluation period was $13.5 \%$ (five patients). Of these, four patients (80\%) died due to sepsis resulting from bronchopneumonia and one patient $(20 \%)$ died due to an episode of upper digestive tract hemorrhage. The other clinical complications comprised two cases (5.4\%) of deep vein thrombosis, one case $(2.7 \%)$ of heel ulcer and one case $(2.7 \%)$ of acute arterial obstruction (Table 1).

From the radiographic evaluation, the mean cervicodiaphyseal angle immediately after the operation was $132.5^{\circ}$, with a standard deviation of 9.8. The reduction after the operation was considered ideal in 31 patients $(83.6 \%)$ (Figure 5), while there were three cases of varus reduction (8.2\%) and three cases of valgus reduction (8.2\%) (Table 2). The mean tip-apex index was 22.8 (standard deviation $=8.3$ ), and $27 \mathrm{pa}$ tients $(73 \%)$ had an index $\leq 25 \mathrm{~mm}$ and the other ten 


\section{Annex 1 - Harris Hip Score}

Hip ID:

Study Hip:Left Right

Examination Date (MM/DD/YY):

Subject Initials: ___ _ _ _

Medical Record Number:

Interval:

\section{Pain (check one)}

None or ignores it (44)

Slight, occasional, no compromise in activities (40)

Mild pain, no effect on average activities, rarely moderate

pain with unusual activity; may take aspirin (30)

Moderate Pain, tolerable but makes concession to pain.

Some limitation of ordinary activity or work. May require

Occasional pain medication stronger than aspirin (20)

Marked pain, serious limitation of activities (10)

Totally disabled, crippled, pain in bed, bedridden (0)

Limp

None (11)

Slight (8)

Moderate (5)

Severe (0)

\section{Support}

None (11)

Cane for long walks (7)

Cane most of time (5)

One crutch (3)

Two canes (2)

Two crutches or not able to walk (0)

\section{Distance Walked}

Unlimited (11)

Six blocks (8)

Two or three blocks (5)

Indoors only (2)

Bed and chair only (0)

\section{Sitting}

Comfortably in ordinary chair for one hour (5)

On a high chair for 30 minutes (3)

Unable to sit comfortably in any chair (0)

Enter public transportation

Yes (1)

No (0)

\section{Stairs}

Normally without using a railing (4)

Normally using a railing (2)

In any manner (1)

Unable to do stairs (0)

Put on Shoes and Socks

With ease (4)

With difficulty (2)

Unable (0)

Absence of Deformity (All yes $=4$; Less than $4=0$ )

Less than $30^{\circ}$ fixed flexion contracture

Less than $10^{\circ}$ fixed abduction

Less than $10^{\circ}$ fixed internal rotation in extension

Limb length discrepancy less than $3.2 \mathrm{~cm}$

Range of Motion (*indicates normal)

Flexion $\left({ }^{*} 140^{\circ}\right)$

Abduction $\left({ }^{*} 40^{\circ}\right)$

Adduction $\left({ }^{*} 40^{\circ}\right)$

External Rotation $\left({ }^{*} 40^{\circ}\right)$

Internal Rotation $\left({ }^{*} 40^{\circ}\right)$

Range of Motion Scale

$211^{\circ}-300^{\circ}(5)$

$161^{\circ}-210^{\circ}(4)$

$101^{\circ}-160^{\circ}(3)$

$61^{\circ}-100(2)$

$31^{\circ}-60^{\circ}(1)$

$0^{\circ}-30^{\circ}(0$

Range of Motion Score

Total Harris Hip Score 
Table 1 - Postoperative clinical complications.

\begin{tabular}{c|c|c}
\hline Clinical complications & N & $\%$ \\
\hline No complication & 28 & 75.7 \\
\hline Mortality & 5 & 13.5 \\
\hline Deep vein thrombosis & 2 & 5.4 \\
\hline Acute arterial obstruction & 1 & 2.7 \\
\hline Heel ulcer & 1 & 2.7 \\
\hline Total & 37 & 100 \\
\hline
\end{tabular}

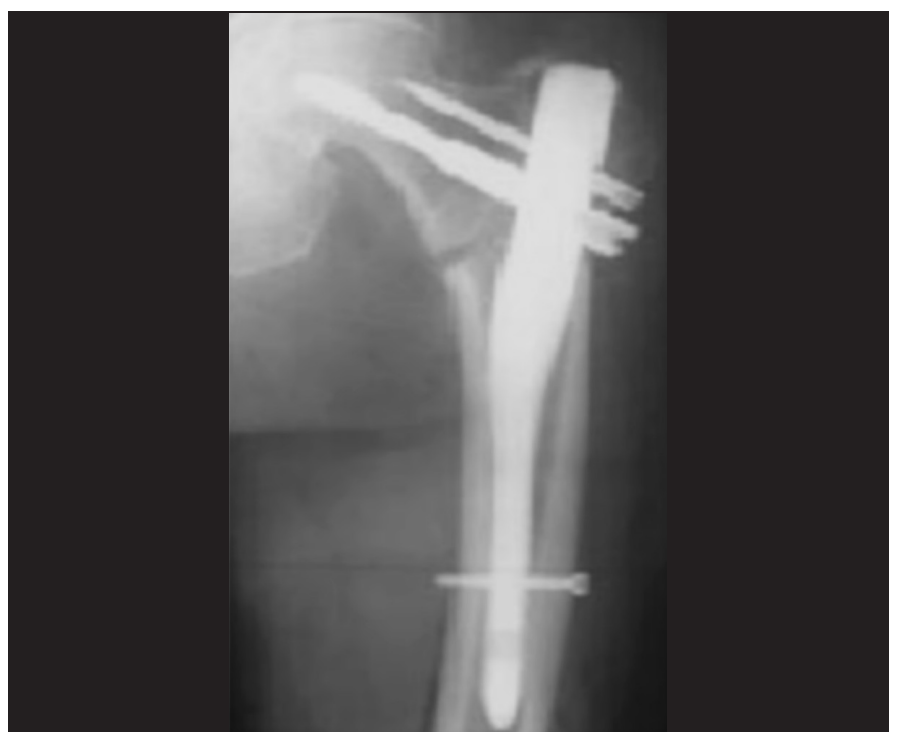

Figure 5 - Anteroposterior radiograph on hip, with ideal reduction.

Table 2 - Cervicodiaphyseal angle measurement.

\begin{tabular}{c|c|c}
\hline Cervicodiaphyseal angle AP & $\mathbf{N}$ & $\%$ \\
\hline Varus $\left(<130^{\circ}\right)$ & 3 & 8.2 \\
\hline Ideal $\left(130^{\circ}-135^{\circ}\right)$ & 31 & 83.6 \\
\hline Valgus $\left(>135^{\circ}\right)$ & 3 & 8.2 \\
\hline Total & 37 & 100 \\
\hline
\end{tabular}

patients (27\%) had an index $>25 \mathrm{~mm}$ (Table 3). After one year of follow-up, the mean cervicodiaphyseal angle was $131.7^{\circ}$, with a standard deviation of 9.3 . There were no cases of varus collapse. Consolidation was confirmed in all the patients six months after the operation, except in one case that presented "cut-out" one month after the operation. This case then underwent resection arthroplasty and consolidation count not be assessed (Annex 2). This was the only case of "cut-out" $(2.7 \%)$ found in the present study.

Cut-out consists of migration of the proximal screws superolaterally in relation to the head, with extrusion and loss of cephalic fixation (Figure 6). This patient then underwent resection arthroplasty for pain relief. This was the only case that required a new surgical procedure. There were no cases of peri- implant fracture.
Table 3 - Tip-apex index measurement.

\begin{tabular}{c|c|c}
\hline Tip-apex index & $\mathbf{N}$ & $\%$ \\
\hline$\leq 25 \mathrm{~mm}$ & 27 & 73 \\
\hline$>25 \mathrm{~mm}$ & 10 & 27 \\
\hline Total & 37 & 100 \\
\hline
\end{tabular}
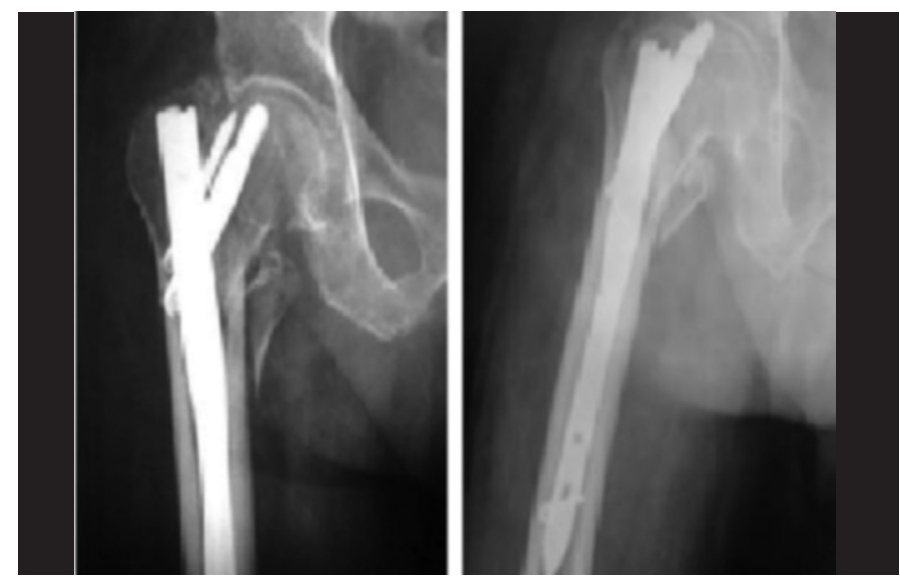

Figure 6 - Anteroposterior and lateral radiographs on right hip with cut-out.

The functional assessment using the Harris score one year after the operation showed that the mean was 69.2 with a standard deviation of 9.3 . In $16 \%$ of the patients, the result presented was excellent, $19 \%$ good, $28 \%$ reasonable and $38 \%$ poor. The Harris scale showed a statistically significant inverse relationship with age $(p=0.023)$, with a coefficient of -0.0402 , i.e. younger ages were associated with higher Harris scores (Figure 7). The Harris score was not influenced by the fracture classification according to the $\mathrm{AO} /$ ASIF system (Table 4).

The evaluation of the progression of walking showed that the quality of walking gradually improved over the assessment period. Despite the instructions to gradually start walking early on, as tolerated, 35 patients $(94.6 \%)$ did not do any active walking during the first week, but only bore weight on the limb.

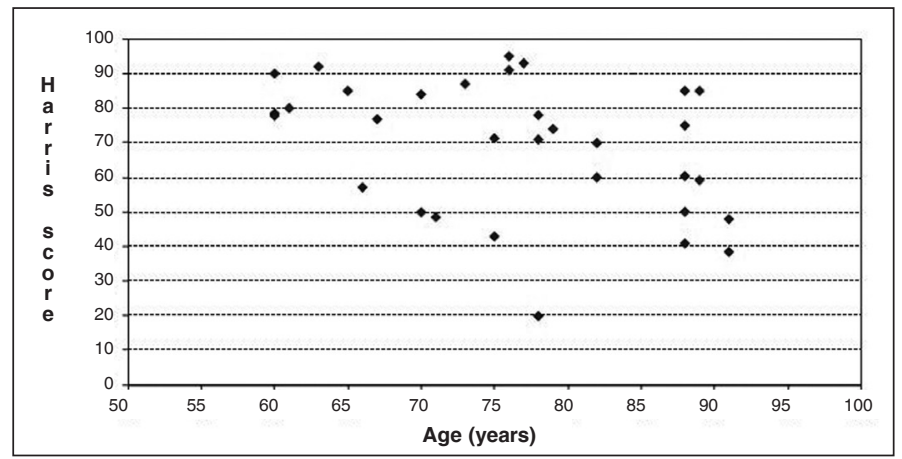

Figure 7 - Harris score versus age. 
Annex 2 - Clinical, functional and radiographic assessment on the patients who underwent osteosynthesis using a cephalomedullary nail.

\begin{tabular}{|c|c|c|c|c|c|c|c|c|c|c|c|c|c|}
\hline & Age & Tronzo & Ao & Side & Time $\mathbf{i}$ & Time c & Sex & Comorbidity & Complications & $\hat{A}$ ap & $\hat{A}$ ap $f$ & Tai & Harris \\
\hline$A$ & 82 & III & $\mathrm{A} 2$ & $\mathrm{R}$ & 12 & 10 & $\mathrm{~F}$ & COPD & Death & 135 & * & 24 & * \\
\hline $\mathrm{B}$ & 94 & V & A3 & L & 6 & 3 & $\mathrm{~F}$ & SAH-DM & Death & 160 & * & 20 & * \\
\hline $\mathrm{C}$ & 86 & III & $\mathrm{A} 2$ & $\mathrm{R}$ & 8 & 6 & $F$ & Alzheimer & Death & 130 & * & 25 & * \\
\hline $\mathrm{D}$ & 88 & IV & $\mathrm{A} 2$ & L & 15 & 13 & $M$ & SAH-DM-COPD & Death & 130 & * & 25 & * \\
\hline$E$ & 83 & III & $\mathrm{A} 2$ & $\mathrm{R}$ & 16 & 11 & M & SAH-Alzheimer & Death & 150 & * & 24 & * \\
\hline $\mathrm{F}$ & 76 & III & $\mathrm{A} 2$ & L & 15 & 13 & $\mathrm{M}$ & $\begin{array}{l}\text { AMI-SAH- } \\
\text { Angioplasty }\end{array}$ & 0 & 125 & 125 & 20 & 95 \\
\hline $\mathrm{G}$ & 77 & III & $\mathrm{A} 2$ & $\mathrm{R}$ & 8 & 5 & $\mathrm{~F}$ & SAH-DM & 0 & 130 & 130 & 20 & 93 \\
\hline $\mathrm{H}$ & 63 & V & A3 & $\mathrm{R}$ & 8 & 5 & $\mathrm{~F}$ & $\mathrm{SAH}$ & 0 & 130 & 130 & 18 & 92 \\
\hline I & 76 & III & $\mathrm{A} 2$ & $\mathrm{R}$ & 8 & 4 & $\mathrm{~F}$ & SAH & 0 & 130 & 130 & 20 & 91.01 \\
\hline $\mathrm{J}$ & 25 & V & $\mathrm{A} 3$ & $\mathrm{R}$ & 4 & 6 & $M$ & 0 & 0 & 115 & 120 & 35 & 90 \\
\hline $\mathrm{L}$ & 73 & V & A3 & $\mathrm{R}$ & 18 & 15 & $M$ & SAH-DM & 0 & 125 & 127 & 30 & 87 \\
\hline$M$ & 65 & V & A3 & $\mathrm{R}$ & 15 & 12 & $F$ & SAH-DM & 0 & 135 & 135 & 20 & 85 \\
\hline $\mathrm{N}$ & 88 & III & $\mathrm{A} 2$ & $\mathrm{R}$ & 7 & 5 & $F$ & DM & 0 & 135 & 135 & 27 & 85 \\
\hline O & 89 & III & $\mathrm{A} 2$ & $\mathrm{R}$ & 7 & 5 & $\mathrm{~F}$ & SAH-DM & AAO & 130 & 130 & 25 & 85 \\
\hline $\mathrm{P}$ & 70 & III & $\mathrm{A} 2$ & L & 18 & 15 & $F$ & $\mathrm{SAH}$ & 0 & 137 & 137 & 15 & 84 \\
\hline Q & 61 & III & $\mathrm{A} 2$ & $\mathrm{R}$ & 7 & 5 & $\mathrm{M}$ & 0 & 0 & 110 & 118 & 10 & 80 \\
\hline $\mathrm{R}$ & 54 & III & $\mathrm{A} 2$ & L & 7 & 4 & $M$ & $\begin{array}{l}\text { SAH-Previous } \\
\text { Stroke }\end{array}$ & 0 & 135 & 135 & 40 & 78.48 \\
\hline$S$ & 78 & III & $\mathrm{A} 2$ & $\mathrm{R}$ & 5 & 3 & $M$ & $\begin{array}{l}\text { Depression- } \\
\text { Myeloma }\end{array}$ & 0 & 150 & 153 & 25 & 78 \\
\hline $\mathrm{T}$ & 58 & V & A3 & L & 6 & 3 & $F$ & $\begin{array}{l}\text { SAH-DM-CRF- } \\
\text { Hypothyroidism }\end{array}$ & 0 & 136 & 136 & 27 & 77.85 \\
\hline$U$ & 67 & V & $\mathrm{A} 3$ & L & 8 & 6 & $\mathrm{~F}$ & SAH & 0 & 130 & 130 & 30 & 76.85 \\
\hline V & 88 & III & $\mathrm{A} 2$ & L & 5 & 3 & $\mathrm{M}$ & SAH-DM & 0 & 130 & 130 & 25 & 75 \\
\hline$x$ & 79 & III & $\mathrm{A} 2$ & L & 18 & 15 & $F$ & $\begin{array}{l}\text { DM-SAH- } \\
\text { Atrial Flutter }\end{array}$ & 0 & 125 & 125 & 20 & 74 \\
\hline Z & 75 & III & $\mathrm{A} 2$ & $\mathrm{R}$ & 6 & 3 & $\mathrm{~F}$ & $\begin{array}{l}\text { DM-SAH- } \\
\text { Alcoholism }\end{array}$ & 0 & 130 & 130 & 35 & 71.3 \\
\hline $\mathrm{A} 1$ & 78 & III & $\mathrm{A} 2$ & L & 7 & 6 & $\mathrm{~F}$ & 0 & 0 & 130 & 130 & 5 & 71 \\
\hline B2 & 82 & III & $\mathrm{A} 2$ & $\mathrm{R}$ & 7 & 5 & $\mathrm{~F}$ & 0 & 0 & 130 & 130 & 10 & 70 \\
\hline $\mathrm{C} 1$ & 88 & III & $\mathrm{A} 2$ & L & 7 & 4 & $M$ & Parkinson & Heel Ulcer-DVT & 130 & 130 & 18 & 60.41 \\
\hline D1 & 82 & V & $\mathrm{A} 3$ & $\mathrm{R}$ & 7 & 4 & $M$ & DM & 0 & 135 & 135 & 25 & 60 \\
\hline E1 & 89 & III & $\mathrm{A} 2$ & L & 9 & 6 & $\mathrm{~F}$ & SAH-DM & 0 & 130 & 130 & 20 & 59.22 \\
\hline $\mathrm{F} 1$ & 66 & III & $\mathrm{A} 2$ & L & 6 & 4 & $\mathrm{~F}$ & SAH & DVT & 130 & 130 & 20 & 57.15 \\
\hline G1 & 88 & III & $\mathrm{A} 2$ & L & 7 & 5 & $\mathrm{~F}$ & SAH & 0 & 135 & 135 & 25 & 50.15 \\
\hline $\mathrm{H} 1$ & 70 & IV & $\mathrm{A} 2$ & $\mathrm{R}$ & 20 & 18 & $M$ & Parkinson-SAH & 0 & 135 & 135 & 30 & 50 \\
\hline 11 & 71 & III & $\mathrm{A} 2$ & $\mathrm{R}$ & 7 & 5 & $\mathrm{~F}$ & 0 & 0 & 135 & 135 & 14 & 48.57 \\
\hline J1 & 91 & III & $\mathrm{A} 2$ & $\mathrm{R}$ & 20 & 14 & $M$ & 0 & Cut-out & 130 & 130 & 40 & 48 \\
\hline L1 & 75 & III & $\mathrm{A} 2$ & $\mathrm{~L}$ & 13 & 4 & $\mathrm{~F}$ & Parkinson & 0 & 140 & 140 & 21 & 43 \\
\hline M1 & 88 & IV & $\mathrm{A} 3$ & L & 8 & 4 & $\mathrm{~F}$ & $\begin{array}{c}\text { Epilepsy- } \\
\text { Hypothyroidism }\end{array}$ & 0 & 130 & 130 & 24 & 41 \\
\hline N1 & 91 & III & $\mathrm{A} 2$ & L & 15 & 10 & $\mathrm{~F}$ & SAH-DM & 0 & 130 & 130 & 2 & 38.57 \\
\hline 01 & 78 & III & A3 & L & 6 & 4 & $M$ & Epilepsy & 0 & 140 & 140 & 30 & 20 \\
\hline
\end{tabular}

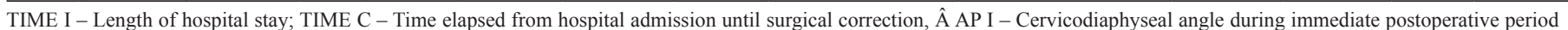
Â AP F - Cervicodiaphyseal angle one year after surgery; TAI - Tip-apex index; * - Impossible to assess; AAO - Acute arterial obstruction 
Table 4 - Harris scale for AO/ASIF classification.

\begin{tabular}{c|c|c|c|c}
\hline AO & N & Mean & Standard deviation & p-value* $^{*}$ \\
\hline A2 & 23 & 68.9504 & 16.95327 & 0.895 \\
\hline A3 & 9 & 69.9667 & 24.86849 & 0.895 \\
\hline
\end{tabular}

At the assessment two months after the operation, it was observed that only three patients $(8.6 \%)$ were not walking actively. Six months after the operation, only $3.1 \%$ were still not walking, while $50 \%$ were walking with the aid of stick, $34.4 \%$ with a walking frame and $12.5 \%$ without using any aid (Figure 8 ). Before the fracture, $16.2 \%$ of the patients were already using a walking frame, $34.3 \%$ were using a stick and 59.5\% were walking unaided.

The evaluation on the evolution of pain by means of the visual analogue scale graduated from 0 to 10 showed that there was a progressive diminution over the assessment period, with a mean of 5.19 in the first week and 2.25 one year after the surgery (Figure 9).

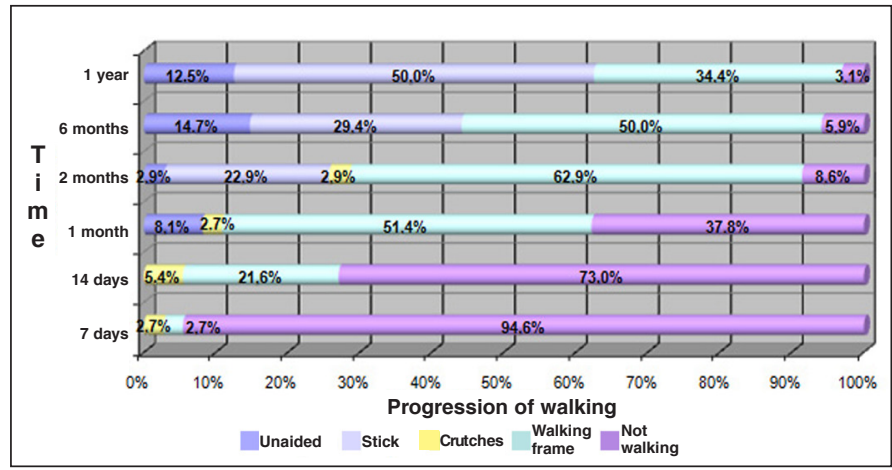

Figure 8 - Time versus progressing of walking.

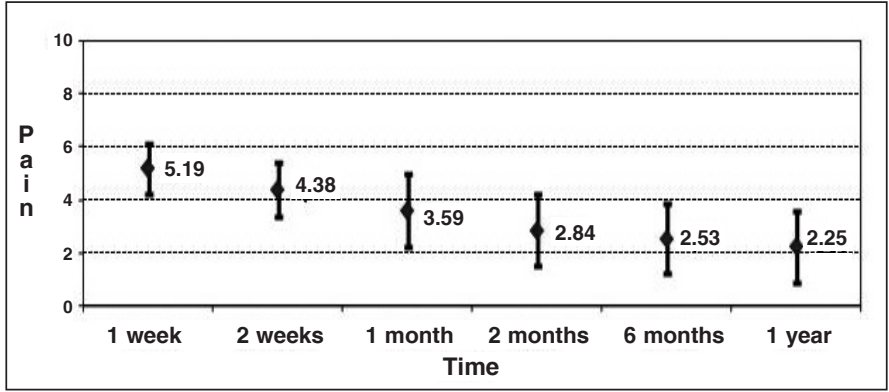

Figure 9 - Pain scale versus time.

\section{DISCUSSION}

Trochanteric fractures are correlated with high morbidity and mortality rates. The most prevalent and most important clinical complications are deep vein thrombosis, pulmonary thromboembolism, superficial infection and deep infection ${ }^{(4)}$.
The general incidence of mortality after trochanteric fractures is described in the current literature as 6 to $11 \%$ within the first month and 14 to $36 \%$ within the first year ${ }^{(16)}$. Mortality typically results from cardiopulmonary, thromboembolic and septic complications. In our sample, the mortality rate was $13.5 \%$ (five patients) over the one-year period. The cause of death was sepsis due to bronchopneumonia in four cases $(80 \%)$, while one case $(20 \%)$ was due to upper digestive tract hemorrhage.

Deep vein thrombosis (DVT) is a substantial cause of morbidity and mortality during the follow-up of cases of fracture of the proximal femur ${ }^{(4)}$. Symptomatic DVT occurs in around $2 \%$, and $85 \%$ of these cases are diagnosed during the first five weeks after the fracture. Factors such as prolonged immobility, coagulopathy and delayed surgical treatment favor occurrences of $\mathrm{DVT}^{(17)}$. In the present study, antithrombotic drug prophylaxis was instituted in all cases, and two patients (5.4\%) were diagnosed with DVT. No cases of pulmonary thromboembolism were found among our sample.

No cases of superficial or deep infection were identified in the present study. The other clinical complications were one case $(2.7 \%)$ of acute arterial obstruction and one case $(2.7 \%)$ of pressure ulcer on the heel.

According to Schipper et $\mathrm{al}^{(8)}$, the most common postoperative complication seen in radiological evaluations is cut-out. Its incidence has been described in the literature as 0.7 to $10.6 \%{ }^{(2)}$. In the present study, there was only one case of cut-out $(2.7 \%)$. Inadequate reduction, especially with varus presentation, incorrect implant positioning and advanced osteoporosis are the factors that determine its occurrence.

Implant positioning should follow the concepts introduced by Baumgaertner et $\mathrm{al}^{(12)}$, in which the distance between the tip of the sliding screw and the center of the femoral head should not be more than 25 $\mathrm{mm}$, as a sum of the AP and lateral-view radiographs (tip-apex index $<25 \mathrm{~mm}$ ), which facilitates telescoping of the dynamic system of the implant and reduces the risk of cut-out ${ }^{(15)}$. Also according to Baumgaertner et $\mathrm{al}^{(12)}$, occurrences of cut-out increase considerably when the tip-apex index is greater than $25 \mathrm{~mm}$, independent of the quality of the fracture reduction. The tip-apex index has been described for osteosynthesis using a DHS. Use of this index for assessing the adequacy of positioning of cephalomedullary nails remains controversial, especially with regard to nails 
with two screws fixed proximally, because of the difficulty in positioning the sliding screw at the center of the femoral head in AP-view radiographs. Thus, there is a greater tendency towards positioning the sliding screw at a lower location on AP radiographs, especially in patients with a short femoral head and neck.

Despite this proviso, this index has been used by some authors for assessing whether implants have been positioned correctly ${ }^{(15)}$. In our study, we found a mean tip-apex index of 22.8 (standard deviation of 8.3). There were 27 patients $(73 \%)$ with a tip-apex index $\leq 25 \mathrm{~mm}$ and $10(27 \%)$ with an index $>25 \mathrm{~mm}$. Even with the presence of the anti-rotation nail in the Targon-PF, we were able to respect the principles recommended by Baumgartner, for most of our patients. The patient in this study who presented cut-out had advanced osteoporosis and inadequate implant positioning (tip-apex index of $40 \mathrm{~mm}$ ), as risk factors.

Werner-Tutschku et $\mathrm{al}^{(18)}$ reported that the main reason for occurrences of cut-out is an initial unsatisfactory reduction, generally with varus presentation. As well as favoring occurrences of cut-out, varus alignment may result in Trendelenburg gait. In our sample, the mean cervicodiaphyseal angle was $132.5^{\circ}$, with a standard deviation of 9.3 . The postoperative reduction was considered to be ideal in 31 patients $(83.6 \%)$, and there were three cases with varus reduction $(8.2 \%)$ (Table 2). According to Werner-Tutschku et al, the incidence of varus consolidation is $11.2 \%{ }^{(18)}$. The angular deviation did not favor cut-out and did not statistically influence the quality of gait in this sample $(p=0.442)$.

In a meta-analysis, Kaplan et $\mathrm{al}^{(2)}$ presented a mean time taken to achieve consolidation of four months, independent of the device used. On the other hand, Bride et $\mathrm{al}^{10}$ reported that consolidation occurred after an average of six months. According to Crawford et $\mathrm{al}^{(19)}$, the consolidation rate found among patients treated with a cephalomedullary nail was $89 \%^{(19)}$. In the present study, consolidation was observed in all the patients after six months, except for one case that presented cut-out one month after the operation, who then underwent resection arthroplasty. Consequently, consolidation could not be assessed. The abundant blood supply in the trochanteric region, associated with stable synthesis, favored this result.

One complication from using cephalomedullary nails is fractures of the femoral diaphysis below the tip of the implant ${ }^{(7)}$. Lack of experience on the part of the surgeon and the inadequate design of first and second-generation nails have favored this complication ${ }^{(14)}$. Nails of the latest generation have a radius of curvature that fits the anatomical shape of the femur better. In contrast with older reports, recent studies have reported significant decreases in this complication ${ }^{(2)}$. The rate of diaphyseal fracture below the nail tip ranges in the literature from zero to $2.1 \%{ }^{(2)}$. In the present study, no cases of fractures distal to the implant were found.

With regard to functional evaluation, the Harris score is the scale used by the majority of authors for postoperative functional assessment of trochanteric fractures ${ }^{(16)}$. Schipper et al ${ }^{(8)}$ found a mean score of 66.80 (standard deviation $=17.94)$ with a proximal femoral nail of $\mathrm{PFN}^{\circledR}$ type, and 69.50 (standard deviation = 16.00) with a nail of Gamma Nail ${ }^{\circledR}$ type, after one year. The mean value found in the present study was 69.3 (standard deviation $=9.3$ ) with the Targon-PF ${ }^{\circledR} ; 16 \%$ of the patients presented excellent results, $19 \%$ good, $28 \%$ reasonable and $38 \%$ poor. The functional result according to the Harris score was considered to be poor or moderate for the majority of the patients who underwent osteosynthesis with a cephalomedullary nail. The great difficulty in functional assessment of fractures of the proximal femurs using the Harris score is that it is impossible to make an assessment before the surgery and thus, no comparisons from before to after the operation can be made, as used in elective surgery. Given the advanced age of these patients, with preexisting limitations, they would possibly present scores that are already compromised. One important indicator is that the Harris score showed a statistically significant correlation with age (Figure 7), and was not influenced by the Tronzo and AO classifications, and not even by the quality of the reduction and positioning of the implants. Thus, the energy of the trauma and the quality of the surgery, evaluated radiographically, did not influence the functional result, but the patient's age significantly influenced the functional result, such that older patients had worse results (coefficient: -0.0402). The previous functional level of these more elderly patients was probably already worse than that of the younger patients, which influenced these results. Therefore, from our point of view, a new scale for use in functional assessments on hip fractures needs to be developed, since the Harris score is more indicated for elective surgery such as hip arthroplasty to treat arthrosis, because of its comparative possibilities. 
With a new scale, it would be possible to better assess the influence of the trauma energy and the quality of the surgery in functional assessments, after removing the influence of the patient's previous state from the assessment. We emphasize that even though the mean Harris score of 69.3 found in the present study is low, it is similar to values found by other authors ${ }^{(16)}$. For a better functional assessment on the patients, we analyzed another two important parameters separately: recovery of walking ability and evolution of the pain scale.

According to Pajarinen et $\mathrm{al}^{(13)}$, patients who underwent osteosynthesis with a cephalomedullary nail, in unstable trochanteric fractures, presented a significantly faster return to their previous level of walking ${ }^{(13)}$. Herrera et $\mathrm{al}^{(9)}$ reported on a study involving 250 patients treated with the $\mathrm{PFN}^{\circledR}$ and Gamma nail ${ }^{\circledR}$ cephalomedullary nails, in which around $50 \%$ of the patients had recovered their previous walking capacity, one year after the surgery ${ }^{(4)}$. In the present study, we assessed the recovery of walking ability over the course of time. We divided the subjects into five groups: no walking; walking with a frame; walking with crutches; walking with a stick; and walking unaided (Figure 8). The greatest evolution in the quality of walking occurred over the first two months after the operation, such that only $8.6 \%$ of the patients were still not walking at that time. One year after the operation, only $3.1 \%$

\section{REFERENCES}

1. Parker MJ, Handoll $\mathrm{HH}$. Intramedullary nails for extracapsular hip fractures in adults. Cochrane Database Syst Rev. 2009;(3):CD004961.

2. Kaplan K, Miyamoto R, Levine BR, Egol KA, Zuckerman JD. Surgical management of hip fractures: an evidence-based review of the literature. II. Intertrochanteric fractures. J Am Acad Orthop Surg. 2008;16(11):665-73.

3. Haidukewych GJ. Intertrochanteric fractures: ten tips to improve results. J Bone Joint Surg Am. 2009;91(3):712-9.

4. Todd CJ, Freeman CJ, Camilleri-Ferrante C, Palmer CR, Hyder A, Laxton CE, et al. Differences in mortality after fracture of the hip: the east Anglian audit. Br Med J. 1995;310(6984):904-8.

5. Müller ME. Classification and international AO-Documentation of femur fractures. Unfallheilkunde. 1980;83(5):251-9.

6. Tronzo RG. Symposium on fractures of the hip. Special considerations in management. Orthop Clin North Am. 1974;5(3):571-83.

7. Laros G, Moore JF. Complications of fixation in intertrochanteric fractures. Clin Orthop Relat Res. 1974;(101):110-9.

8. Schipper IB, Steyerberg EW, Castelein RM, van der Heijden FH, den Hoed PT, Kerver AJ, et al. Treatment of unstable trochanteric fractures. Randomised comparison of gamma nail and the proximal femoral nail. J Bone Joint Surg Br. 2004;86(1):86-94.

9. Herrera A, Domingo LJ, Calvo A, Martinez A, Cuenca J. Comparative study of trochanteric fractures treated with the Gamma nail or the proximal femoral nail. Int Orthop. 2002;26(6):365-9.

10. Bridle SH, Patel AD, Bircher M, Calvert PT. Fixation of intertrochanteric fractures of the femur. A randomized prospective comparison of the gamma nail and the dynamic hip screw. J Bone Joint Surg Br. 1991;73(2):330-4.

11. Schipper IB, Bresina S, Wahl D, Linke B, van Vugt AB, Schneider E, et al. Biomechanical evaluation of the proximal femoral nail. Clin Orthop Related Res. 2002;(405):277-86. of the patients were still not walking, while $50 \%$ were walking with the aid of a stick, $34.4 \%$ with a walking frame and $12.5 \%$ without any aid. Thus, one year after the operation, $40.6 \%$ of the patients presented same walking capacity as presented previously.

An assessment of pain was made by Nuber et al ${ }^{(20)}$, through a six-month follow-up with successive scores, comparing patients who received a DHS with those who received an intramedullary nail. The pain scores were considerably greater in the group treated with intramedullary nails. In the present study, the patients were assessed using a visual analogue scale for pain and showed progressive diminution of pain at the return visits over the one-year period, as presented in Figure 9. The evolution of the pain scale was not influenced by the trauma energy, age, reduction parameters or implant positioning parameters.

\section{CONCLUSION}

Osteosynthesis using a cephalomedullary nail Targon ${ }^{\circledR}-\mathrm{PF}$, used in unstable trochanteric fractures, resulted in low rates of clinical complications, excellent stabilization, few mechanical complications and adequate functional results. The authors consider that this is an appropriate technique for treating unstable trochanteric fractures of the femur.

12. Baumgaertner MR, Curtin SL, Lindskog DM. Intramedullary versus extramedullary fixation for the treatment of intertrochanteric hip fractures. Clin Orthop Related Res. 1998;(348):87-94

13. Pajarinen J, Lindahl J, Michelsson O, Savolaien V, Hirvensalo E. Pertrochanteric femoral fractures treated with a dynamic hip screw or a proximal femoral nail. A randomised study comparing post-operative rehabilitation. J bone Joint Surg Br. 2005;87(1):76-81.

14. Helwig P, Faust G, Hindenland U, Hirschmüller A, Konstantinidis L, Bahrs C, et al. Finite element analysis of four different implants inserted in different positions to stabilize an idealized trochanteric femoral fracture. Injury. 2009;40(3):288-95.

15. Guimarães JA, Guimarães AC, Franco JS. Avaliação do emprego da haste femoral curta na fratura trocantérica instavel do fêmur. Rev Bras Ortop. 2008; 43(9):406-417.

16. Guimarães RP, Alves DP, Silva GB, Bittar ST, Ono NK, Honda E, et al. Tradução e adaptação transcultural do instrumento de avaliação do quadril "Harris Hip Score". Acta Ortop Bras. 2010;18(3):142-7.

17. Hefley FG, Nelson CL, Puskarich-May CL. Effect of delayed admission to the hospital on the preoperative prevalence of deep-vein thrombosis associated with fractures about the hip. J Bone Joint Surg Am. 1996;78(4):581-3.

18. Werner-Tutschku W, Lajtai G, Schmiedhuber G, Lang T, Pirkl C, Orthner E. Intra-and perioperative complications in the stabilization of per-and subtrochanteric femoral fractures by means of PFN. Unfallchirurg. 2002;105(10):881-5.

19. Crawford $\mathrm{CH}$, Malkani AL, Cordray S, Roberts CS, Sligar W. The trochantheric nail versus the sliding hip screw for intertrochanteric hip fractures: a review of 93 cases. J Trauma. 2006; 60(2):325-8.

20. Nuber S, Schönweiss T, Rüter A. Stabilisation of unstable trochanteric femoral fractures. Dynamic hip screw (DHS) with trochanteric stabilisation plate vs. proximal femur nail (PFN). Unfallchirurg. 2003;106(1):39-47. 